Short Paper

\title{
A Study of Susceptibility of Sex Reversal after a Single 2-Hour Treatment of Androgen in Amago Salmon
}

\author{
Masaru Nakamura \\ Department of Biology, Faculty of Medicine, Teikyo University, Hachioji, Tokyo 192-03, Japan \\ (Received November 4, 1993)
}

\begin{abstract}
Key words: sex differentiation, masculinization, methyltestosterone, sex reversal, susceptibility to exogenus sex steroid, amago salmon, a single treatment, all-female
\end{abstract}

Sex steroids effectively induce sex reversal when given at early stages of gonadal development in teleost fish. ${ }^{1,2)}$ Baker et al. ${ }^{3)}$ and Piferrer and Donaldson ${ }^{4)}$ successfully masculinized alevins with a single treatment of methyltestosterone (MT) at $20-400 \mu \mathrm{g} / \mathrm{l}$ for $2 \mathrm{~h}$ around the time of hatching. This single-treatment method of inducing sex reversal makes it possible to pinpoint not only the time of peak susceptibility to exogenous sex steroids, but also the important period of gonadal sex differentiation. In order to establish the time exogenous androgen most effectively induces sex reversal, genetically controlled all-female alevins of the amago salmon Oncorhynchus rhodurus were treated with a single short treatment of MT at various stages of gonadal development.

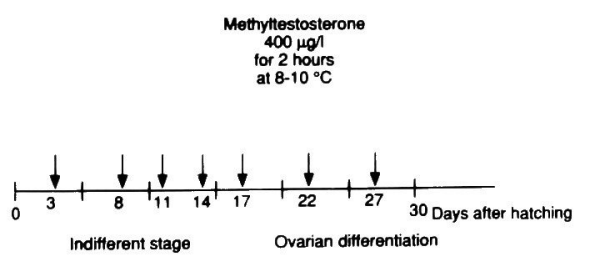

Fig. 1. Experimental treatment cohorts.

Each arrow indicates the age at which an experimental cohort of 50 fish received a single treatment of methyltestosterone $(400 \mu \mathrm{g} / l)$.

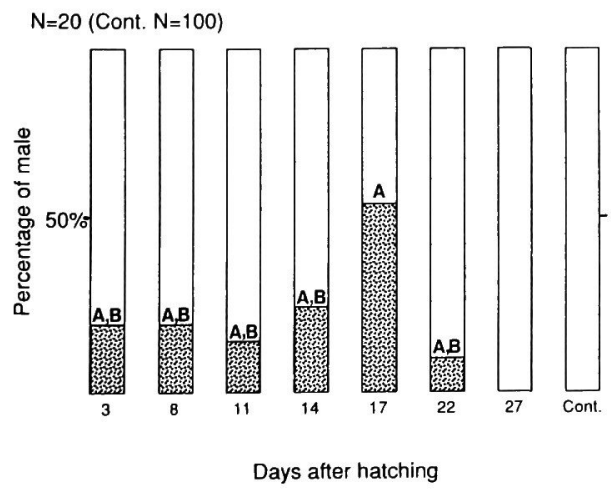

Fig. 2. Percentage of males in each cohort showing susceptibility to methyltestosterone-induced sex reversal.

Letter A indicates a significant difference from $100 \%$ females in the control group. (Fisher's exact test, $p<0.001$ ). Letter B indicates a significant difference from the sex ratio in the cohort treated at 17 DAH (Fisher's exact test, $0.1<p<0.01$ )
All-female, eyed eggs were obtained from mating pseudo-male $(\mathrm{XX})$ with normal female $(\mathrm{XX})$. They were transferred from Gifu Prefecture Experimental Fish Station to Teikyo University in Tokyo. They were cultivated in fully aerated water at $8-10^{\circ} \mathrm{C}$ until use. Fifty alevins each at 3 , $8,11,14,17,22$, and 27 days after hatching (DAH) (3-30, Dec. 1990) were immersed for $2 \mathrm{~h}$ in water containing $400 \mu \mathrm{g} / l \mathrm{MT}$ (Fig. 1). As a control, 150 fish were immersed for $2 \mathrm{~h}$ in $1 /$ water containing $1 \mathrm{~m} l$ ethanol only. Immediately after steroid treatment, autopsies were performed on about 20 individuals from each cohort to assess the effect of the hormone on sex differentiation.

At $100 \mathrm{DAH}, 10$ individuals were selected from each time cohort, and the number of males was recorded for each. Their gonads were examined histologically. At $200 \mathrm{DAH}$, male count and histological examination were also done for the remaining 10 fish for each cohort. Normal ovarian differentiation was observed ultrastructurally.

The percentage of sex reversed males in each group is

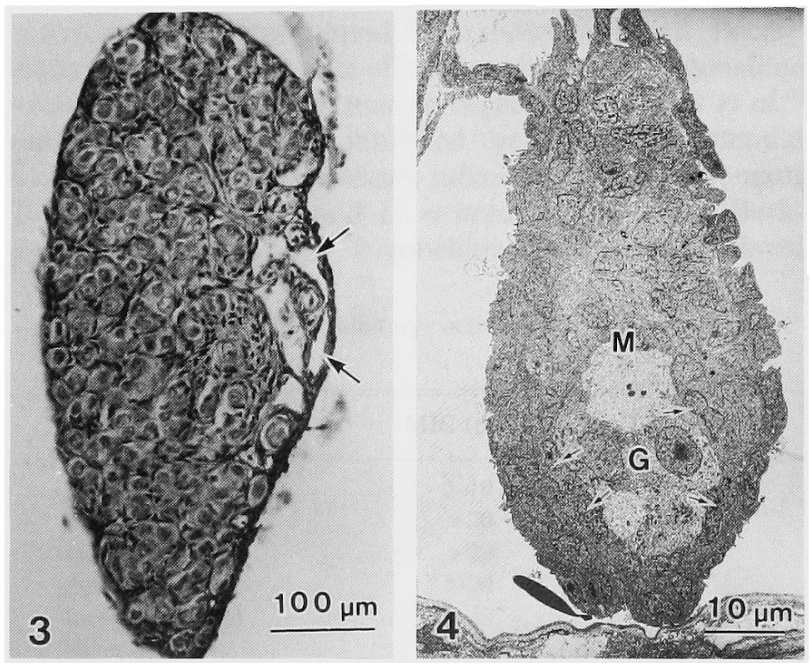

Fig. 3. An O. rhodurus testis at $200 \mathrm{DAH}$.

This specimen was obtained from the 17 DAH treatment cohort Efferent ducts (arrows) and spermatogonia are seen, indicating normal testicular differentiation. $\times 115$.

Fig. 4. Electron micrograph of an O. rhodurus gonad of control fish at $17 \mathrm{DAH}$.

Meiotic division of gonal germ cell $(M)$ is seen. Arrows indicate presumed granulosa cells. G., gonial germ cell. $\times 820$. 
shown in Fig. 2. The highest percentage converting to male occurs at $17 \mathrm{DAH}$. In this group $55 \%$ had normal testes with developed efferent ducts and some spermatogonia (Fig. 3). Fish treated at 3-14 and 22 DAH showed lower percentages ( $10-25 \%)$ of conversion to male. No males were found in the cohort treated at $27 \mathrm{DAH}$ or in the control group (100 specimens). These results show that the amago salmon at $17 \mathrm{DAH}$ are more susceptible to exogenous androgen in sex reversal than in the other groups. It should be noted that some fish were also susceptible to MT to change sex from female to male at 3-14 and 22 DAH. This fact indicates that the time of susceptibility to exogenous androgen differs between individuals of this species, though the peak occurs around 17 DAH. Thus, long term treatment covering the susceptible period is necessary to obtain $100 \%$ sex reversal, as shown by Usuda. ${ }^{5)}$ It is essential to conduct further experiments using pure lines to determine whether this individual difference of susceptibility is genetic or a physiological factor.

Transformation of oogonia to meiotic oocytes in amago salmon gonads provided evidence of ovarian differentiation. ${ }^{6)}$ This transformation occurred at $20-25$ DAH. Active mitotic division of oogonia in the cysts, an increase of presumed granulosa cells in the cysts, and other somatic cells characterized female gonads at 17 DAH (Fig. 4). This corresponds to the time of development both in germ cells and in somatic cells just prior to ovarian differentiation.

I thank Mrs. Y. Tachikawa and T. Kuwata, Gifu Prefecture Experimental Fish Station, for donating the eyed eggs of the amago salmon. This study was supported in part by a Grant-in-Aid for Scientific Research (Nos. 05660220 and 06660252) from the Ministry of Education, Science, and Culture of Japan to MN.

\section{References}

1) F. Yamazaki: Aquaculture, 33, 329-354 (1983).

2) G. A. Hunter and E. M. Donaldson: in "Fish Physiology" (ed. by W. S. Hoar, D. J. Randall, and E. M. Donaldson), Vol. IX Part B, Academic Press, New York, 1983, pp. 223-303.

3) I. J. Baker, I. I. Solar, and E. M. Donaldson: Aquaculture, 72, 359-367 (1988).

4) F. Piferrer and E. M. Donaldson: Aquaculture, 77, 251262 (1989).

5) H. Usuda: Fish Genetics and Breeding Science, 14, 11-22 (1989) (in Japanese).

6) M. Nakamura and Y. Nagahama: Aquaculture, 112, 237-251 (1993). 